\title{
A Comparison of Skin Microbiota under Adhesive Bandages versus Uncovered Adjacent Skin
}

\author{
Kendra Lemire, Felicia Maes, Marialis Ginart, Chris VanFleet \\ and Tim Braun \\ Biological Sciences Department \\ State University of New York at Oswego \\ 7060 Route 104 \\ Oswego, New York 13126-3599 USA
}

Received: January 13, 2013

Accepted: March 20, 2013:

\begin{abstract}
The skin is the largest organ in the human body and interacts directly with the exterior environment. It is also a habitat for bacteria. We are interested in the perturbing effects of adhesive bandages on the skin's bacterial populations. We compared covered versus uncovered finger skin using three kinds of over the counter adhesive bandages. We found that skin covered with an adhesive bandage is home to approximately 80 fold more culturable bacteria than is uncovered skin and that type of bandage makes little difference to expansion of the bacterial population. Diversity of bacteria was measured by two different techniques: one culture dependent and one culture independent, both found no significant diversity difference between covered vs. uncovered skin in number of taxa present. The culture dependent analysis found that most samples were dominated by a single bacterium, whereas the culture independent 16S rDNA analysis found more diversity. Evidence of seasonal cycling of dominant culturable skin bacteria was observed.
\end{abstract}

\section{INTRODUCTION}

Humans are hosts to a large number of very complex networks of microbes on the skin and other mucosal surfaces. Human microbiota are made up of very diverse groups of bacteria that have evolved with their host organism. Human microbiota composition varies between different sampling sites on an individual, across individuals, and with time for the same sampling sites [1]. The interaction between humans and bacteria is important to human health [2]. The human microbiota helps to ward off pathogenic species both by direct competition and by the secretion of compounds that restrict the growth of invading species.

The benefits of human associated microbes are best studied in the gastrointestinal microbiota. This microbiota is the largest in the human body in its quantitative mass and qualitative diversity which are essential for survival [3]. The GI microbiota play an important role in metabolism by synthesizing vitamins, metabolizing bile salts, degrading xenobiotics and breaking indigestible starches via fermentation [4]. The Gl microbiota also play an important role in the immune system maturation at birth by developing a tolerance to a variety of microbial antigens [5].

An important but less well studied microbiota of the body is found on the skin (recently reviewed by Kong 2011 [6]). This microbiota is made up of a more limited number of bacterial species. This is a direct consequence of the harsh environments that skin is exposed to [7]. Among other things, the survival of bacteria on the skin depends on factors such as $\mathrm{pH}$, humidity, temperature, concentration of inhibitors and amount of available nutrients. The skin microbiota is also influenced and regulated by antimicrobial peptides secreted by human cells. These antimicrobial peptides affect the number and composition of the colonizing 
bacteria [8]. Sex and handedness are also factors in skin microbiota composition [9].

Aside from the uncontrollable factors mentioned above, it has been shown that the hygienic care of skin by the individual also affects skin microbiota. Hand washing alters the microbiota of the skin by either rinsing away the bacteria itself or inducing growth of bacteria due to damaged skin [10]. Time since last hand washing likewise affects the composition [9]. The healing process can also be sped up with the application of bandages. While the ultimate purpose of a bandage is to protect the damaged skin from foreign organisms, drying and further injury, it may also serve as a conducive environment for bacterial growth.

The purpose of this experiment is twofold, first to explore the differences in microbiota of uncovered skin versus skin covered by several types of over the counter commercial bandages (Band-Aid® brand). Secondly to compare whole cell matrix assisted laser desorption - time of flight (MALDI-ToF) mass spectrometry based identification of bacteria with evaluation of microbiota based on 16S rRNA sequence profiling. MALDI-Tof is generally faster than 16S rDNA analysis but is not as sensitive, being limited to bacteria that can be cultured. We hypothesize that the harsh, aerobic skin surface microbiota will be well represented in culture and thus make MALDI-Tof analysis representative of the bacteria found there.

Fingers were swabbed to collect samples of bacteria on uncovered fingers and fingers covered with adhesive bandages on the same hand. The identification of the collected and cultured organisms was carried out using whole cell MALDI-TOF mass spectrometry and for a subset of samples $16 \mathrm{~S}$ rDNA sequencing.

MALDI-TOF mass spectrometry can be used to identify bacteria on the basis of a mass fingerprint consisting of molecules common to that bacterium. It is a rapid and relatively high throughput technique where a laser impacts a dried sample suspended in an organic salt matrix to create ions [11]. The mass/charge spectrum of common molecules from a bacterium, called a whole cell fingerprint, is often unique and can be used to identify them [12]. In current configurations this techniques requires an entire bacterial colony, meaning that the organism in question must be able to be grown in culture.

Bacteria can also be identified by comparing their 16S rRNA sequence to sequences in public databases. To obtain the 16S rRNA sequence from an organism one can use PCR to amplify the 16S rRNA sequence directly from DNA in environmental samples. This technique then has the dual advantages that it is both very sensitive and does not require that the bacterial population being analyzed be grown in culture. The ability to study bacteria that cannot be grown in culture can be important, considering that the vast majority of bacteria cannot be readily cultured in the lab [13]. The use of the 16S rRNA gene to study bacterial phylogeny has become very popular as this gene is present is all bacteria, the function of the gene has not changed over a long period of time and the gene itself is big enough for some informatics purposes [14].

\section{METHODS AND MATERIALS}

\section{a. Study Population:}

The participants in this study were undergraduate students in either a microbiology course or in a directed research course. The students were informed that their participation was entirely voluntary and that no class credit or monetary remuneration would be provided and that they could withdraw from the project at any time. The methods used in this study are also being used in a larger study and have been approved by the SUNY Oswego Human Subjects Committee.

b. Data collection and morphological classification

Band-Aid ${ }^{\circledR}$ brand "flexible fabric" (breathable, non-waterproof), "tough-strips" (waterproof), and "plus antibiotic waterproof" (pad coated in ointment, each gram of which contains 10,000 units of polymyxin B and 500 units of bacitracin as per information on box) over the counter adhesive bandages were used in the study. Three bandages of each type were used straight out of the box to assess bacterial load on the packaged bandages. Test bandages were opened in a 
laminar flow hood with gloved hands and sterile cotton swabs dipped in sterile buffered saline $(100 \mathrm{mM} \mathrm{NaCl}, 20 \mathrm{mM}$ Tris $\mathrm{HCl} \mathrm{pH} \mathrm{7.4)} \mathrm{used} \mathrm{to} \mathrm{swab} \mathrm{only} \mathrm{the} \mathrm{non-}$ adhesive pad of the bandage, the entire pad surface was swabbed. The swab was then dipped into a sterile microfuge tube containing $1.0 \mathrm{~mL}$ of sterile buffered saline and plunged up and down for 5 strokes to transfer material to the saline. A $0.1 \mathrm{~mL}$ aliquot of the saline was then spread onto LB agar plates and incubated at $30^{\circ} \mathrm{C}$. The plates were assessed for growth at 24 and 48 hours of incubation.

Each bandage covered approximately $4 \mathrm{~cm}^{2}$ of undamaged skin on the finger of a healthy human volunteer. Bandages were worn on the test subject's left and right index fingers on the $1^{\text {st }}$ phalanx (gap between first knuckle and base of finger) for 24 hours. Each subject used the same bandage type on both hands.

After 24 hours, four samples were collected by swabbing the covered skin (index fingers) and uncovered skin (middle fingers) with a sterile cotton swab wetted in sterile buffered saline. The swab was then plunged into a sterile micro-centrifuge tube containing $1.0 \mathrm{~mL}$ of sterile saline as described above. The covered samples were diluted $1 / 20$ with sterile saline and 0.1 $\mathrm{mL}$ of each sample were plated on tryptic soy agar (TSA), Luria-Bertani (LB) agar, or nutrient agar plates. To the undiluted sample, Lysozyme (Hen egg white, Sigma) was then added to $5 \mathrm{ug} / \mathrm{mL}$ and sterile glycerol to $15 \%$, followed by freezing at $80^{\circ} \mathrm{C}$ for long term storage and $16 \mathrm{~S}$ rDNA analysis. The agar plates were incubated at $30^{\circ} \mathrm{C}$ for 48 hours. The colonies on each plate were counted and broken up into morphological classes based on color, shape, and texture.

\section{c. Mass spectrometry analysis}

Colony morphological groups from each plate were analyzed by MALDI-ToF mass spectrometry. Five colonies in each colony morphology class were spotted onto a steel target plate using a sterile toothpick and allowed to dry. The matrix a-cyanocinnamuric acid dissolved to $20 \mathrm{mg} / \mathrm{mL}$ in $50 \%$ acetonitrile/ $49 \%$ water/ $1 \%$ trifluoroacetic acid was added as a $2 \mu \mathrm{l}$ drop to each sample and allowed to dry. The samples were analyzed on a Bruker Daltronics Autoflex MALDI system. Laser power was adjusted as needed but averaged $30 \%$. Spectra were generated using 100 summed laser shots per run and enough runs made per sample to bring the most intense peaks to about 2000 absolute intensity units per summed spectrum to assist comparison of spectra.

The five mass fingerprints in each morphological grouping were compared to one another visually using the FlexAnalysis software package that came with the mass spectrometer. Spectra were smoothed and baseline subtracted in FlexAnalysis. Overlay of spectra and visual comparison in FlexAnalysis was used as an initial method for binning similar spectra. Once bins of similar spectra were compiled, mass lists were downloaded into Excel and similarity between $\mathrm{m} / \mathrm{z}$ peaks on different spectra was measured with a Pearson's product moment of correlation coefficient (cut off value 0.85 for considering peaks in different spectra to be the same). In some cases it became clear that not all colonies in a morphology group were the same bacterium. In this case additional colonies in that morphology class were spotted to collect a total of five spectra for the new grouping. This process continued until each morphologically classified bacterium from each plate had five similar mass fingerprints or there were no more colonies to analyze. Lastly, all the mass fingerprints from different samples were also compared to create a master list of different bacteria identified by MALDIToF.

\section{d. Streak for isolated colonies}

Once all the organisms were grouped, one colony from each group was streaked on a TSA agar plate using threesector streak technique. The plates were incubated at $30^{\circ} \mathrm{C}$ for 48 hours. One colony from each plate was collected and prepared for mass spectrometry as described above. Mass fingerprints were created and compared to the previously collected data to confirm identity. This same culture was used to create a freezer stock for the organism if the mass fingerprints matched. Freezer stocks were made to $15 \%$ glycerol final concentration from a $75 \%$ glycerol stock and stored at $-80^{\circ} \mathrm{C}$. 


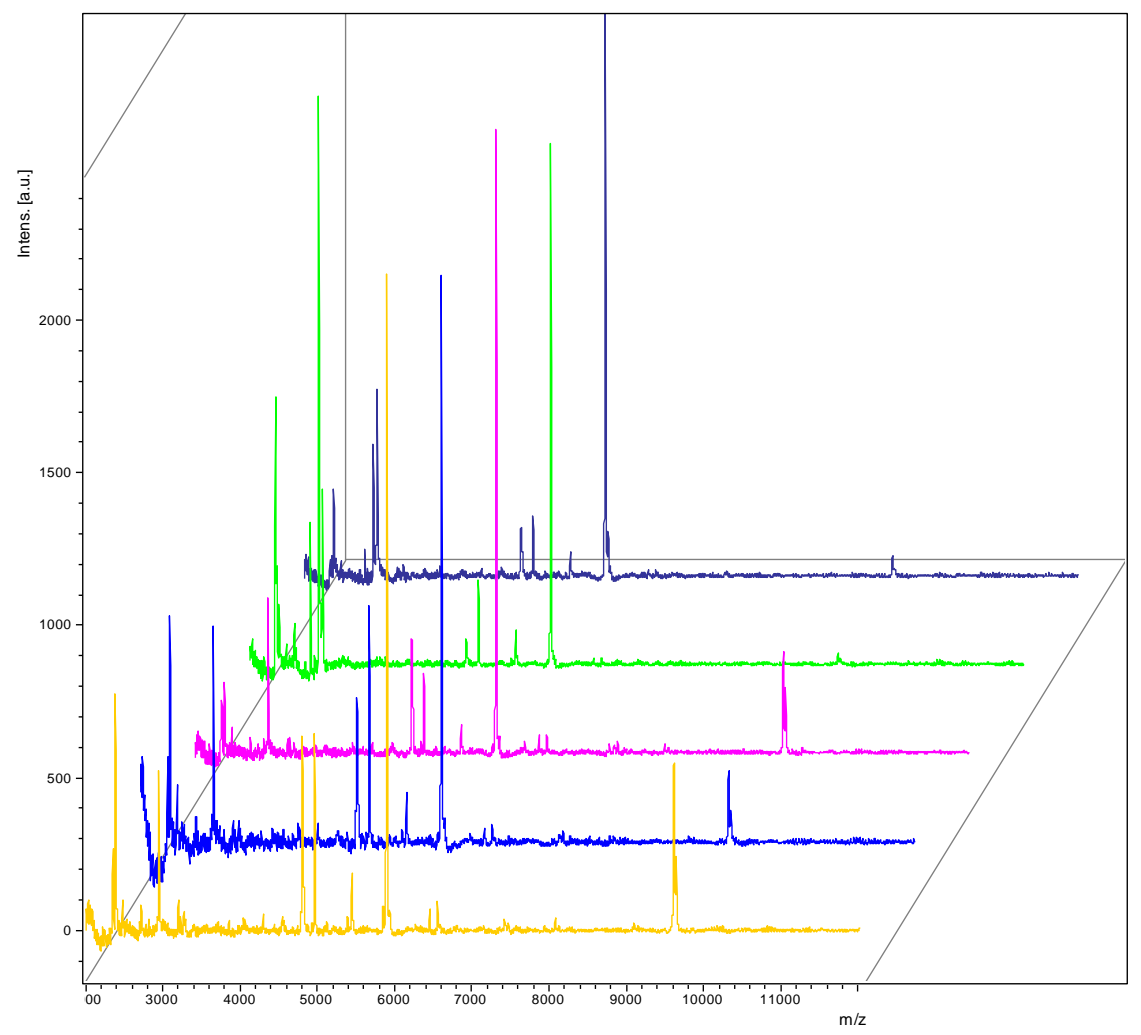

Figure 1. MALDI-Tof whole cell spectra. Shown above are mass spectra from $2000-12,000 \mathrm{~m} / \mathrm{z}$ for 5 different colonies from the same colony morphology grouping in a single sample.

e. PCR amplification, cloning, and sequencing $16 \mathrm{~S}$ rRNA

Total bacterial 16S rDNA was amplified directly from skin swabs using the Phusion PCR kit (NEB), and primers 63f (5'CAGGCCTAACACATGCAAGTC-3') and 1387r (5'-GGGCGGWGTGTACAAGGC-3'). The cycling conditions were: 3 min hot start $\left(98^{\circ} \mathrm{C}\right)$, followed by 44 cycles of $95^{\circ} \mathrm{C}$ for 20 $\mathrm{sec}, 52^{\circ} \mathrm{C}$ for $30 \mathrm{sec}$, and $72^{\circ} \mathrm{C}$ for $60 \mathrm{sec}$. The resulting PCR fragments were separated on $1.5 \%$ agarose gels and the band at approximately $1.3 \mathrm{Kbp}$ excised with a clean razor blade. DNA was purified from the gel slices using the Qiagen gel extraction kit. Once purified, the DNA fragments were cloned using the Topo Cloning® kit (Invitrogen). Cloned DNA was then transformed into E. coli "Top 10" cells (Invitrogen) and plated on LB $+50 \mu \mathrm{g} / \mathrm{mL}$ kanamycin and incubated for 20 hours at $37^{\circ} \mathrm{C}$. Colonies of the $\mathrm{LB}+\mathrm{Kan}$ plates were grown in LB $+35 \mu \mathrm{g} / \mathrm{mL}$ kanamycin for 16 hours at $37^{\circ} \mathrm{C}$. Plasmids were isolated from the overnight cultures using the miniprep kit from BioBasic (Buffalo NY, USA). Insert DNA was sequenced with T7 promoter (5'TAATACGACTCACTATAGGG-3') and T3 promoter (5'-AATTAACCCTCACTAAAG-3') primers using the DTCS Sanger sequencing kit (Beckman-Coulter). Sequencing reactions were analyzed on a CEQ8000 micro-capillary system (Beckman-Coulter). Sequences were edited in BioEdit and submitted to the Ribosomal Database Project (RDP) project as Fasta files [8], or used directly in BLAST searches. The dominant organism(s) on each plate, once obtained in pure culture, were also subjected to $16 \mathrm{~S}$ rDNA analysis as described above, except that the starting material was whole cells from a colony on a plate.

\section{RESULTS}

\section{a. Culture Based Assessment of Skin Microbiota}

Controls assessing the presence of bacteria on the adhesive bandage pads 


\begin{tabular}{|l|c|c|c|c|c|}
\hline $\begin{array}{c}\text { Bandage } \\
\text { Type }\end{array}$ & $\begin{array}{c}\text { \# of } \\
\text { Samples } \\
\text { Analyzed }\end{array}$ & $\begin{array}{c}\text { Fold Difference } \\
\text { Between } \\
\text { Covered \& } \\
\text { Uncovered }\end{array}$ & $\begin{array}{c}\mathrm{X}^{2} \\
\text { difference } \\
\boldsymbol{p} \text { value }\end{array}$ & $\begin{array}{c}\text { \# of Taxonomic } \\
\text { Units (Covered) } \\
\text { Average }\end{array}$ & $\begin{array}{c}\text { \# of Taxonomic } \\
\text { Units } \\
\text { (Uncovered) } \\
\text { Average }\end{array}$ \\
\hline $\begin{array}{l}\text { Flexible } \\
\text { Fabric }\end{array}$ & 5 & $87+/-106$ & 0.36 & $2.8+/-0.6$ & $3.2+/-1.9$ \\
\hline Waterproof & 6 & $94+/-142$ & 0.13 & $1.5+/-0.6$ & $2.2+/-0.4$ \\
\hline $\begin{array}{l}\text { Waterproof } \\
\text { + Antibiotic }\end{array}$ & 6 & $60+/-64$ & 0.052 & $3.2+/-1.7$ & $2.2+/-1.3$ \\
\hline
\end{tabular}

Table 1. Comparison of covered vs. uncovered skin for three adhesive bandage types. ${ }^{*}$ Note: $p$ is probability level for $\mathrm{X}^{2}$ test.

straight out of the box showed that the bandages were largely sterile and not a significant source of introduced bacteria (data not shown). Nine healthy volunteers wore bandages for 24 hours on the $1^{\text {st }}$ phalanx of either the $2^{\text {nd }}$ or $3^{\text {rd }}$ fingers of each hand with the bandage pad facing inward. After 24 hours skin swabs were taken from both the region covered by the bandage and a similar region of skin on an adjacent uncovered finger. Bacteria able to grow on trypic soy, LB, or nutrient agar plates after 48 hours at $30^{\circ} \mathrm{C}$ were counted and then sorted into categories based on colony morphology (shape, texture, color, wetness, smooth or rough edges, etc.) as initial proxies for taxonomic groups. MALDIToF mass spectrometry of whole cells from colonies was then used to compare colonies within and across morphology groups. Five different colonies from each morphology group were analyzed. In most cases the final number of taxonomic groups for a plate was lower after MALDI analysis, as in many cases several different colony morphology groups proved to be the same bacterium. A case in which all five colonies in a morphology group were the same bacterium is shown in Figure 1.

There was a significant increase in the number of bacteria present on skin under the adhesive bandages but not an increase in diversity of cultured bacteria as opposed to uncovered skin, Table 1. On average there was an 80 fold increase in the number of bacteria in the covered vs. the uncovered samples from the same individual. In no cases were there fewer cultured bacteria in a covered skin sample than an uncovered skin sample.

There was a significant increase in the number of bacteria present on skin under the adhesive bandages but not an increase in diversity of cultured bacteria as opposed to uncovered skin, Table 1. The range of values for the total bacterial counts is quite large because the actual CFU counts on plates ranged over almost 3 orders of magnitude so the simple arithmetic average fold difference is presented (standard deviation is shown to give a rough idea of the total range). On average there was about an 80 fold increase in the number of bacteria in the covered versus the uncovered samples from the same individual. In no cases were there fewer cultured bacteria in a covered skin sample than an uncovered skin sample.

In most cases it was noted that there was one most numerous cultured bacterium in a sample. Often this dominant bacterium accounted for $95 \%$ or more of the colonies on a plate. This same bacterium was dominant on both covered and uncovered samples for an individual and only the magnitude of the population differed. It also became apparent that this same bacterium was dominant on samples from other individuals. In fact, of the 7 individuals sampled in the initial stage of the project two groups of three individuals had the same dominant bacterium. In the initial sampling during late February 2009 four individuals were sampled, three of these individuals had the same dominant bacterium by BLAST search of $16 \mathrm{~S}$ rDNA, namely Brevibacterium linena at $4 \mathrm{e}^{-120}$. The 


\begin{tabular}{|c|c|c|c|}
\hline \multicolumn{2}{|c|}{ Covered Sample } & \multicolumn{2}{c|}{ Uncovered Samples } \\
\hline (right hand) & Bacterium & (right hand) & (left hand) \\
\hline 1 & Anearococcus & 1 & 2 \\
\hline 2 & Acinetobacter & 0 & 0 \\
\hline 6 & Microccineae & 23 & 6 \\
\hline 1 & Peptonophilus & 0 & 0 \\
\hline 8 & Flavobacteriaceae & 0 & 0 \\
\hline 10 & Enterobacteriacea & 2 & 1 \\
\hline 7 & Corynebacterium & 6 & 0 \\
\hline 5 & Actinomycetales & 5 & 1 \\
\hline 1 & Staphlyococcus & 1 & 17 \\
\hline 0 & Bacillates & 2 & 0 \\
\hline 0 & Sphingobacteriaceae & 2 & 0 \\
\hline 0 & Pseudomonas & 1 & 0 \\
\hline 0 & Propionibacteria & 1 & 5 \\
\hline 0 & Acidobacteria & 0 & 1 \\
\hline 47 & Total clones & 44 & 34 \\
\hline 9 & Total groups & 10 & 7 \\
\hline
\end{tabular}

Table 2. $16 \mathrm{~S}$ rDNA Clones.

fourth individual had a mixture of bacteria present with no clear dominant bacterium. The second set of samples was collected four weeks later (late March 2009) and consisted of three more individuals who also all had a single dominant bacterium, top BLAST hit for known organisms, Staphlyococcus warneri at $6 \mathrm{e}^{-150}$.

\section{b. Culture Independent Assessment of Skin Microbiota}

To test whether or not our culture based microbiota profile was accurately capturing the bacteria present on the skin we also undertook PCR, cloning, and sequencing of $16 \mathrm{~S}$ rDNA directly from skin swab samples. The skin swabs were collected from a single individual in a separate adhesive bandage trial and were also subjected to colony morphology sorting and MALDI-ToF analysis by the same process as the earlier bandage samples.

We analyzed three samples in detail. Two samples of uncovered skin and one of adhesive bandage covered skin from the same individual. A table of clones is shown in Table 2, a graphical summary of the data at the phylum level of the three experiments is shown in Figure 2. A total of fifty clones were analyzed for each sample. Once short reads (under 250 bp), closed vector, and unidentified samples were removed, 47 clones were left for the adhesive bandage covered sample, 44 for the left hand exposed skin and 34 for the right hand exposed skin. Taxonomic assignment of $16 \mathrm{~S}$ rDNA was done using the Ribosomal Database Project's (RDP) "classifier" algorithm [15]. Numbers of clones for a sample differs between Table 2 and Figure 2 because some clones were only identified down to order or family level.

The results for the samples analyzed by both MALDI and 16S rDNA sequencing are shown in Table 3 . Seven appreciably different groups of spectra, labeled A-G were found by MALDI-ToF across the fours samples (right and left hand, uncovered and covered). Representatives of four of these groups, A$D$, were grown in pure culture and their 16S rDNA amplified by whole cell PCR, cloned, and sequenced. The sequences where identified by the RDP "classifier" algorithm [15] which revealed that bacteria A-D were all Staphlyococcus isolates. Bacterium E failed to be isolated in pure culture and bacteria $F \& G$ were single deviate spectra that were not attempted to be isolated in pure culture.

\section{DISCUSSION}

We found that after 24 hours of coverage, based on cultured bacteria, that there was not much change in the number of 


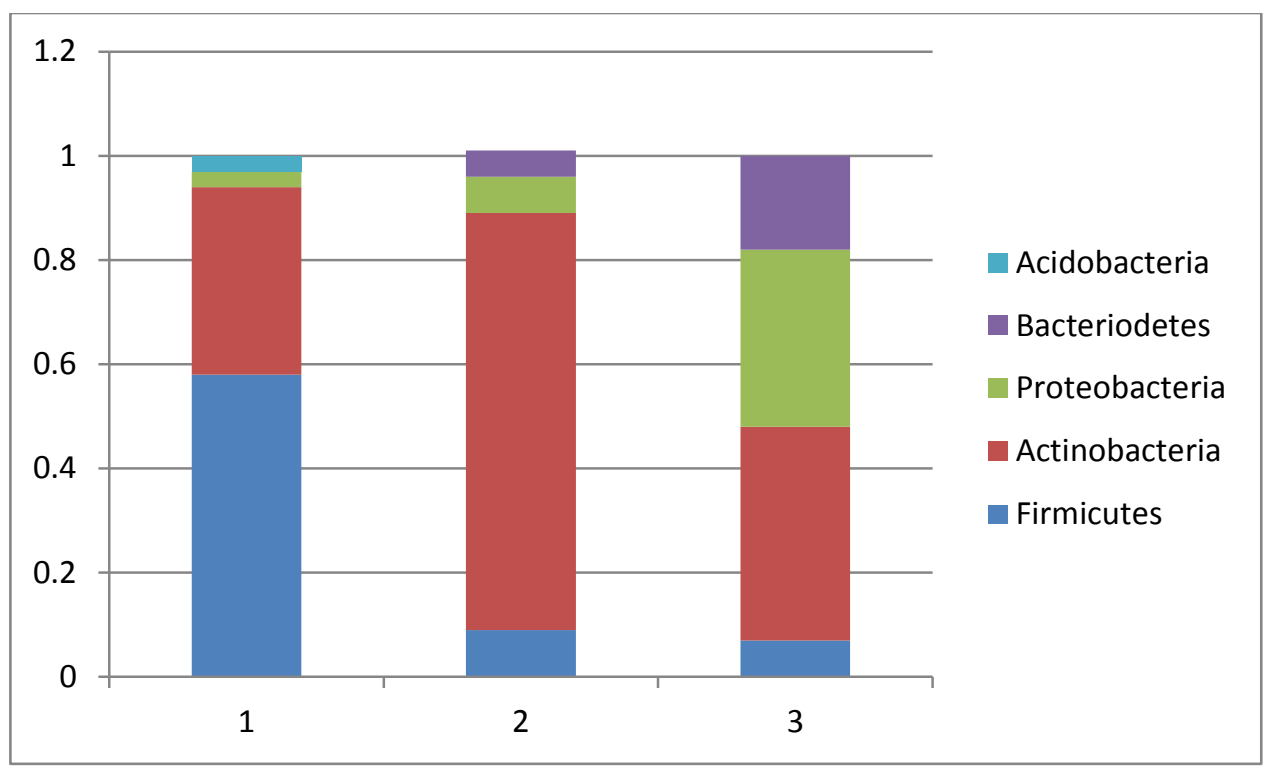

Figure 2. Distribution chart of $16 \mathrm{~S}$ rDNA clones by Phylum. Shown above is a bar chart distribution of $16 \mathrm{~S}$ rDNA clones by bacterial phylum. Samples are: 1) uncovered left hand, 2) uncovered right hand, and 3) covered right hand. Vertical axis is percent of total sample composition.

taxons present on the skin, but that an 80 fold expansion in the number of bacteria (common to both the covered and uncovered samples) had occurred.

The type of bandage used made little difference in either population expansion or diversity. Results for the $x^{2}$ test of deviation among the three bandage categories is shown in Table 1, the "waterproof + antibiotic" total fold increase in bacterial number is borderline for being grouped in with the other bandages with $p=0.052$. This could be an effect of the antibiotic ointment applied to the bandage, but is not a strong correlation, particularly considering the large range of bacterial counts involved. Likely much of the antibiotic ointment is removed by hand washing within the first few hours of the experiment. The antibiotic ointment on the bandage also did not cause a distortion in the diversity of skin bacteria contrary to what might be expected. Either the bacteria are not eliminated by the antibiotic and can recover as it is washed away, and/ or there are deeper reservoirs of bacteria below the skin surface that can repopulate the skin surface once the antibiotic is gone. Evidence for a vertical continuum of bacteria in the skin has been demonstrated [16].

\begin{abstract}
The observation of common dominant bacteria across multiple individuals was not expected and is quite interesting. Even more interesting is the temporal distinction between the two sets of samples. By chance the two sampling intervals occurred before and after spring break 2009. The gap between samplings coincided with a particularly strong spring thaw that year. During the first sampling period average daytime temperatures ranged in the 20's Fahrenheit, low humidity, and continuous snow cover. During the second sampling period average daytime temperatures were in the 40's Fahrenheit, higher humidity, and no snow cover. Whether the seasonal change influenced the change in dominant culturable skin bacteria is hard to prove but the correlation is intriguing.
\end{abstract}

The proportion of bacteria found on the surface of the human body that are culturable varies but is thought to be between $10-20 \%$ and certainly greater than that for other environments such as the soil where values as low as $1 \%$ of all bacteria present can be cultured in the lab [13, 17, 18]. To test whether or not our cultured skin microbiota assessment was representative of the cells actually present on the skin, we 


\begin{tabular}{|c|c|l|l|l|}
\hline Sample & $\begin{array}{l}\text { \#Colonies } \\
\text { Analyzed }\end{array}$ & $\begin{array}{l}\text { Initial } \\
\text { MALDI } \\
\text { Taxons }\end{array}$ & $\begin{array}{l}\text { Final } \\
\text { MALDI } \\
\text { Taxons }\end{array}$ & $\begin{array}{l}\text { 16S rDNA } \\
\text { Taxons } \\
\text { Table\#2 }\end{array}$ \\
\hline $\begin{array}{c}\text { Uncovered } \\
\text { Left }\end{array}$ & 10 & $\mathrm{~B}(5), \mathrm{C}(5)$ & 1 & 6 \\
\hline $\begin{array}{c}\text { Uncovered } \\
\text { Right }\end{array}$ & 25 & $\begin{array}{c}\mathrm{A}(11), \mathrm{B}(5), \\
\mathrm{C}(5), \mathrm{E}(3) \\
\mathrm{F}(1)\end{array}$ & $3(?)$ & 9 \\
\hline $\begin{array}{c}\text { Covered } \\
\text { Right }\end{array}$ & 15 & $\begin{array}{c}\mathrm{B}(5), \mathrm{D}(7) \\
\mathrm{E}(2), \mathrm{G}(1)\end{array}$ & $3(?)$ & 8 \\
\hline
\end{tabular}

Table 3. Summary of Taxon Diversity for Samples Analyzed by both Culture Dependent and Culture Independent Techniques Shown above is a summary for the sample set analyzed by both MALDI and 16S rDNA." \# Colonies Analyzed" refers to the number of colonies examined by MALDI. "Initial MALDI Taxons" is the diversity immediately following MALDI analysis, each taxon is assigned a letter from A-G, number of colonies in each group are shown in ( ). "Final MALDI Taxons" refers to the discovery that MALDI taxa A-D are all Staphlyococcus isolates. MALDI taxa $\mathrm{E}, \mathrm{F}$, and $\mathrm{G}$ could not be analyzed by $16 \mathrm{~S}$ rDNA analysis and their status is indeterminate (denoted by "?"). "16S rDNA Taxons" is a vertical tally of total groups from Table\#2, excluding the possibly duplicate group Actinomycetales (which includes the Corynebacterineae, Micrococcineae, and Propionibacterineae, which are already tallied groups).

subjected three samples from the same individual to analysis using PCR to amplify 16S rDNA directly from skin swabs. PCR product was cloned, transformed, and random colonies sequenced to sample the diversity of $16 \mathrm{~S}$ rDNA present.

The results of the 16S rDNA are somewhat of a mixed bag. There was some continuity in the three samples, a Micrococcineae (genus Rothia) was common to all three samples, giving us confidence that the samples are relevant and not deriving from random contaminants in the PCR reaction. The left hand uncovered sample was dominated by $16 \mathrm{~S}$ rDNA from Staphlyococcus $(50 \%$ of all clones for that sample, see Table 2) as was the cultured plate from that sample $(100 \%$ Staphylococcus, see Table 3). The right hand uncovered sample was dominated by Rothia, $52 \%$ of all clones in the sample, with only a single $16 \mathrm{~S}$ rDNA isolate of Staphlyococcus $(2 \%$ of all clones in the sample). Whereas the right hand uncovered culture plate was at least $84 \%$ Staphylococcus, a significant discrepancy. Apparently Rothia was not cultured under our conditions, but even removing it does not lead to a dominant appearance by Staphlyococcus according to $16 S$ rDNA sampling, although several of the other bacteria identified by $16 \mathrm{~S}$ rDNA in this sample might not be expected to grow in culture as well, possibly leaving just the Staphlyococcus to grow on the culture plate. We are left with one uncovered sample being fairly well represented in both the culture based and non-culture based techniques and the other not well represented at all. This type of discrepancy is why many investigators have switched to exclusively culture independent techniques.

The covered sample also did not show much correlation between the two sampling techniques. The cultured plate of the covered sample was again dominated by Staphylococcus (at least $80 \%$ of colonies) while only a single $16 \mathrm{~S}$ rDNA clone was Staphylococcus. We did not expect the covered sample to be well represented by culture based techniques as its environment is much more moist, protected, and microaerobic than is exposed skin. Many of the bacteria that one would expect to thrive there would not normally grow in aerobic culture.

In terms of diversity both $16 \mathrm{~S}$ rDNA analyzed uncovered skin samples did follow the prediction of the culture based determination; namely that both samples were dominated by a single genus of bacteria (Rothia for the right uncovered sample and Staphylococcus for the left). As expected the 16S rDNA technique turned up more total groups of bacteria than did the culture based technique, but the total 
number of groups was similar between covered and uncovered skin, also the bandage covered skin sample did not show a clear dominant organism by $16 \mathrm{~S}$ rDNA analysis and instead six different groups of bacteria were represented with 5-10 clones each.

Our results for the $16 \mathrm{~S}$ rDNA survey are roughly comparable to the results of similar recent surveys $[1,16,19]$. All three studies showed considerable variation from sample to sample, but with phyla level distributions similar to ours. Our results for the exposed skin did show less contribution from Proteobacteria than the other studies. None of the other studies found single genera of bacteria that were as dominant as those we saw or that were as common among different individuals. One study did also compare cultured results to $16 \mathrm{~S}$ rDNA analysis and found that only $16 \%$ of taxa from fore arm skin could be cultured, our average value is about 18\% [19].

We had hypothesized that exposed finger skin would be more likely to harbor culturable bacteria, due to the relatively harsh conditions experience on the exposed skin of the hand. This proved to be only partially correct with one exposed sample supporting and one not supporting, a larger data set would be required to prove or disprove the hypothesis conclusively.

The primary advantage of the culture dependent method using MALDI-ToF mass spectrometry is its rapid pace and through put. Its disadvantage is that not all bacteria present on the skin surface will grow in culture. The culture independent 16S rDNA amplification approach is more laborious but more through as it does not require growth. Its disadvantage is that there is some question as to whether or not all the bacteria detected are even alive or contributing in a meaningful way to the ecology of the micro-biome.

We are left, then, to wonder at the relative value of the rather striking observation about possible seasonal changes in dominant exposed skin bacterium. It seems reasonable that ambient conditions could favor one bacterium over another on the harsh environment of the skin, but we must face the very real possibility that the correlation reported in this study is an artifact of the culture based technique used to elucidate it.
In conclusion we have shown that adhesive bandage application on the skin does cause a pronounced expansion in bacterial cell number and that, for the types of bandages we tested, bandage type makes little or no difference to the extent of population expansion. In terms of total diversity, there was not much difference between the sampling techniques, both found roughly the same number of groups of bacteria present on covered vs. uncovered skin.

In the future we would propose to revisit the seasonal change hypothesis with a 16S rDNA analysis of more samples and perhaps look at both the fall to winter and winter to spring transitions. It remains an open question as to whether or not culture based analysis can be truly representative of the exposed skin microbiota and would require more samples to be analyzed by both techniques. Given the ability of MALDIToF to provide very specific mass fingerprints of bacteria, it may be better to use the technique to track particular culturable bacteria between micro-biomes rather than to use it for an assessment of all bacteria present in a particular micro-biome.

The elucidation of the importance of the human micro-biome to human health has been gaining pace over the past decade. Investigating the basal and disturbed states of human micro-biomes may provide valuable information on disease states and provides an impetus for further research in this area.

\section{REFERENCES:}

1. Costello EK, Lauber CL, Hamady M, Fierer N, Gordon JI, Knight R (2009) Bacterial community variation in human body habitats across space and time. Science, 236: 1694-1697.

2. Clemente JC, Ursell LK, Parfrey LW, and Knight R (2012) The Impact of the Gut Microbiota on Human Health: An Integrative View. Cell, 148:1258-1270.

3. Neish AS (2009) Microbes in gastrointestinal health and disease. Gastroenterology, 136:65-80.

4. Cover TL, \& Blaser MJ (2009) Helicobacter pylori in health and disease. Gastroenterology, 136:1863-1873. 
5. Mazmanian SK, Liu CH, Tzianabos AO \& Kasper DL (2005) An immunomodulatory molecule of symbiotic bacteria directs maturation of the host immune system. Cell 122:107118.

6. Kong $\mathrm{HH}$ (2011) Skin microbiome: genomics-based insights into the diversity and role of skin microbes. Trends in Mol. Medicine, 17:320-328.

7. Krutmann, J (2009) Pre- and probiotics for human skin. Journal of Dermatological Science, 54:1-5.

8. Cogen AL, Nizet V, Gallo RL (2008) Skin microbiota: a source of disease or defence? Br. J. Dermatol. 158:442-455.

9. Fierera $N$, Hamadye $M$, Lauberb $C L$, Knight R (2008) The influence of sex, handedness, and washing on the diversity of hand surface bacteria. PNAS USA, 104:17994-17999.

10. Rocha LA, Borges LF\& Filho PPG (2009) Changes in hands microbiota associated with skin damage because of hand hygiene procedures on the health care workers. Am J Infect Control, 37: 155-159.

11. Alberts, B, Johnson, A, Lewis, J, Raff, M, Roberts, K, \& Walter, P. (Ed.). (2008). Molecular biology of the cell. New York, NY: Garland Science.

12. Siegrist TJ, Anderson PD, Huen WH, Kleinheinz GT, McDermott CM, Sandrin TR (2007) Discrimination and characterization of environmental strains of Escherichia coli by matrix-assisted laser desorption/ionization time-of-flight mass spectrometry (MALDI-TOF-MS) Journal of Microbiological Methods, 68:554-562.

13. Staley, J.T. and Konopka, A. (1985) Measurement of in situ activities of nonphotosynthetic microorganisms in aquatic and terrestrial habitats. Annu. Rev. Microbiol. 39: 321-346.

14. Janda JM, \& Abbott SL (2007) $16 \mathrm{~s}$ rRNA gene sequencing for bacterial identification in the diagnostic laboratory: pluses, perils and pitfalls. Journal of Clinical Microbiology , 45:27612764.
15. Cole JR, Wang Q, Cardenas E, Fish J, Chai B, Farris RJ, Kulam-SyedMohideen AS, McGarrell DM, Marsh T, Garrity GM and Tiedje JM (2008) The Ribosomal Database Project: improved alignments and new tools for rRNA analysis. Nuc. Acids Res 37: D141D145.

16. Grice EA, Kong HH, Renaud G, Young AC, NISC Comparative Sequencing Program, Bouffard GG, Blakesley RW, Wolfsberg TG, Turner ML, Segre JA (2008) A diversity profile of the human skin microbiota. Genome Res., 18:10431050.

17. Amann RI, Ludwig W, Schleifer $\mathrm{KH}$ (1995) Phylogenetic identification and in situ detection of individual microbial cells without cultivation. Microbiol Rev 59:143-169.

18. Vaughan EE, Schut $F$, Heilig HG, Zoetendal EG, de Vos WM, Akkermans AD (2000) A molecular view of the intestinal ecosystem. Curr Issues Intest Microbiol, 1:1-12.

19. Gao Z, Chi-hong T, Pei Z, Blaser MJ (2007) Molecular analysis of human forearm superficial skin bacterial biota. PNAS USA, 104:2927-2932. 